\title{
Resesarch Sulure \\ Optimizing replenishment base on order structure in crane \& shuttle based storage and retrieval system
}

\author{
Wenkai MA \\ Shandong University \\ Yanyan WANG \\ Shandong University \\ Jinchang HU \\ Shandong University \\ Yaohua WU ( $\nabla$ yhschool_wu@126.com ) \\ Shandong University
}

\section{Original Article}

Keywords: Automatic warehouse sorting system, order structure, replenishment

Posted Date: July 24th, 2020

DOl: https://doi.org/10.21203/rs.3.rs-45972/v1

License: (c) (i) This work is licensed under a Creative Commons Attribution 4.0 International License.

Read Full License 
Title: Optimizing replenishment base on order structure in crane \& shuttle-based storage and retrieval system

\section{Authors:}

Ma Wenkai: School of Control Science and Engineering, Shandong University, Jinan 250061, Shandong, China

e-mail: kevin.ma@mail.sdu.edu.cn

Wang Yanyan:School of Control Science and Engineering, Shandong University, Jinan 250061, Shandong, China

e-mail: 1978_wyy@163.com

Hu Jinchang:School of Control Science and Engineering, Shandong University, Jinan 250061, Shandong, China

e-mail: hooke.1122@mail.sdu.edu.cn

Wu Yaohua(corresponding author):School of Control Science \& Engineering, Shandong University, Jinan 250061, Shandong, China

e-mail: yaohua.wu@sdu.edu.cn

Availability of data and materials : Not applicable

Competing interests: Not applicable

Funding: Not applicable

Authors' contributions: Prof WU Yaohua gives the idea of this study, MA Wenkai and Prof WANG Yanyan build the models and write the manuscript. HU Jinchang improves the manuscript.

Acknowledgements : Not applicable 


\title{
Optimizing replenishment base on order structure in crane $\&$ shuttle-based storage and retrieval system
}

\author{
MA Wenkai, WANG Yanyan, HU Jinchang, WU Yaohua \\ School of Control Science and Engineering, Shandong University, Jinan 250061, China
}

\begin{abstract}
: a new automatic warehouse sorting system, the crane \& shuttle based storage and retrieval system (C\&SBS/RS), is proposed in this paper. In C\&SBS/RS, the crane-based storage and retrieval system $(\mathrm{CBS} / \mathrm{RS})$ in the pallet storage area provides the pallets picking, the shuttle-based storage and retrieval system (SBS/RS) in the tote storage area handles the cases and items picking. When the inventory in SBS/RS is lower than safety stock, SBS/RS initiates replenishment transaction. Besides, the order matrix is proposed to study order structure parameters, such as the order density, the order strength, the wave size and so on. Moreover, this paper analyzes the influence of order structure on the replenishment with four evaluation parameters, e.g., the workload of CBS/RS and SBS/RS, the number of used storage position in SBS/RS, the replenishment time. Numerical experiments are carried out to analysis the impact of the wave size and the proportion of high turnover SKU on those four evaluation parameters under multiple order structure, which is to help warehouse operation manager decide replenishment strategy parameters.
\end{abstract}

Keywords: Automatic warehouse sorting system; order structure; replenishmen

\section{Introduction}

The crane \& shuttle based storage and retrieval system (C\&SBS/RS) is a new variation of the automated storage and retrieval system (AS/RS) and the shuttle-based storage and retrieval system (SBS/RS). The C\&SBS/RS consists of two systems: the cranebased storage and retrieval system (CBS/RS) and the shuttle-base storage and retrieval system (SBS/RS) as illustrated in Fig 1. CBS/RS contains the crane that runs in each aisle and the RGV to connect the I/O point and the $\mathrm{I} / \mathrm{O}$ workstation, which is the same as AS/RS to fulfil the storage and retrieval transaction of pallets. The SBS/RS contains the shuttle running in each tier and the lifter including input lifter and output lifter, which stores totes and fulfils the case picking and the item picking. Therefore, $\mathrm{C} \& \mathrm{SBS} / \mathrm{RS}$ has basic characteristics of AS/RS, such as efficient space utilization and large storage capacity. Moreover, the C\&SBS/RS also has the same flexibility and high throughput as SBS/RS. Consequently, C\&SBS/RS is a batter solution to fulfil the demand of maximum storage density and high throughout with the increasing ratio of the case and item picking in orders.

Orders arrive by waves is one of the most widely used operational policies in distribution centres. In the $\mathrm{C} \& \mathrm{SBS} / \mathrm{RS}$, pallets unloaded from the input trucks are stored in the pallet storage area (i.e., the CBS/RS). When orders arrive, C\&SBS/RS first executes the replenishment operation to the tote storage area (i.e., the SBS/RS). This replenishment operation is that pallets stored in CBS/RS are conveyed to the replenishment workstation and then detached. The SBS/RS supplies the empty totes to store the cases detached from the pallet and then stores these totes for cases and items picking in this wave. To reduce the system workload of replenishment, analyzing and 
merging orders is necessary, i.e., the same stock keeping unit (SKU) of all orders in this wave merges for centralized replenishment. Therefore, analyzing the effect of the order structure of this wave (e.g., the size of order wave, the density of order wave, the strength of order wave) on the replenishment efficiency becomes meaningful.

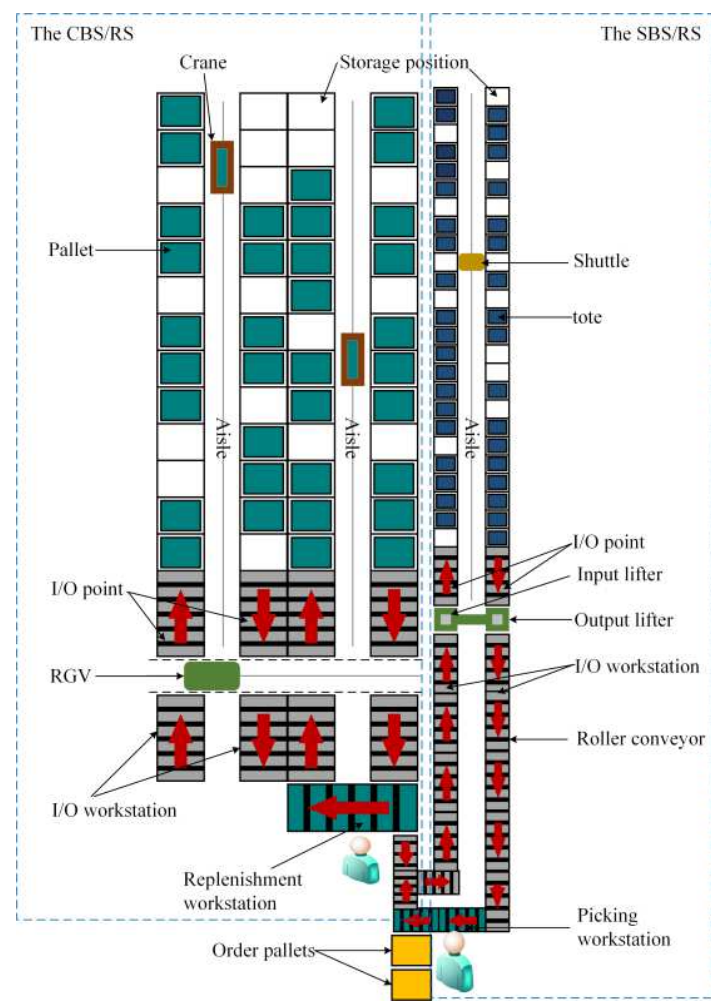

Figure 1. The top view description of the

C\&SBS/RS

Few studies focus on C\&SBS/RS, while numerous papers have studied AS/RS and SBS/RS. Azadeh et al. ${ }^{[1]}$ provided an overview on the robotized and automated warehouse system, such as the crane-based storage and retrieval system, shuttle-based compact storage and retrieval system and robotic mobile fulfilment system, is a more comprehensive introduction about automated warehouse so far. They focused on the research issues and modelling solutions related to the system analysis, design optimization and operations planning and control. Studies on AS/RS can be traced back to $1976^{[2]}$, Hausman et al. studied the storage assignment and proposed that the class-based turnover assignment was the optimal storage assignment in AS/RS. Since then, research on AS/RS has gained momentum and hundreds of papers have been published. Most of the researches focus on the performance of the system (e.g., throughput, cycle time and storage space.) and operation strategies (e.g., task scheduling, storage policies. $)^{[3-6]}$.

In recent years, $\mathrm{SBS} / \mathrm{RS}$, as one type of autonomous vehicle-based storage and retrieval system (AVS/RS), has become very popular in practice and research. Malmborg ${ }^{[7-9]}$ studied the storage and retrieval cycle time, system utilization, and throughput capacity for the tier-to-tier AVS/RS by optimization model. Fukunari and Malmborg ${ }^{[10]}$, Roy et al. ${ }^{[11-12]}$ and Ekren et al. ${ }^{[13-14]}$, used queuing network to model AVS/RS and estimated resource utilization and throughput. Moreover, there is another type AVS/RS named tier-captive AVS/RS, where vehicles are dedicated to a single tier and cannot be transferred to another. Marchet et al. ${ }^{[15] \text { 错误!未找到引用源。 }}$, Wang et al. ${ }^{[16] \text {, }}$ Zou et al. ${ }^{[17]}$ and Tappia et al. ${ }^{[18]}$ proposed applicable queuing network to estimate the performance of the system and compare operation strategies.

However, previous studies hardly considered the impact of the order structure. In fact, different order structures are suitable for different automatic picking systems and operation strategies. SHEN ${ }^{[19]}$ studies the order structure with the grid method to comparing sequential zoning and simultaneous zoning based on order cluster. WANG ${ }^{[20]}$ studied the applicability analysis of AS/RS and Carousel system with different order structures.

The remainder of this paper is as follows. we first describe the replenishment transaction 
in C\&SBS/RS, propose the main assumptions and notations, and analyze the throughput of CBS/RS and SBS/RS respectively. Then, the order matrix is established to study the order structure. The replenishment strategy is described and modelled. Finally, some scenarios with multiple order structures are designed to analyze the influence of order structure on replenishment.

\section{System description}

\subsection{Replenishment transaction}

The replenishment transaction in the $\mathrm{C} \& \mathrm{SBS} / \mathrm{RS}$ is that cases stored in CBS/RS are replenished to SBS/RS. The flow of the replenishment transaction in C\&SBS/RS is shown in Fig 2. When orders arrive, the warehouse management computer first carries out replenishment according to three types of information: i. SKU information, which can supply the SKU type to decide the appropriate replenishment method and the SKU size to calculate the needed number of empty totes; ii. Stock information, that is used to calculate the number of cases should replenish to SBS/RS and monitor the remaining storage positions; iii. Order information, which determines the amount of replenishment. When the replenishment transaction arrives from the warehouse management computer, SBS/RS should process the empty totes retrieval transaction if there are not enough empty totes on replenishment workstation (see Appendix). At the same time, CBS/RS processes the pallet retrieval transaction to supply the inventory (see Appendix). When the pallet inventory, empty totes and pickers are prepared, pickers pick up cases from the pallet and drop to the tote. Then SBS/RS process the storage transaction to store totes (see Appendix). And if there are some remaining cases in pallet,
CBS/RS should process the storage transaction to return pallet (see Appendix).

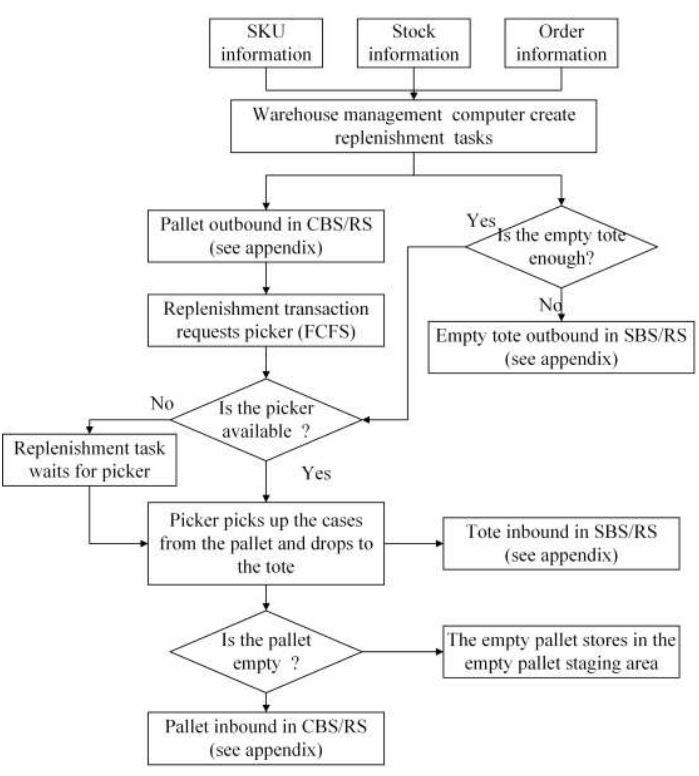

Figure 2. Flowchart of the replenishment transaction in $\mathrm{C} \& \mathrm{SBS} / \mathrm{RS}$

\subsection{Main assumption}

The assumption of C\&SBS/RS in this study are listed below:

- As most previous contribution (e.g. Ekren et al. ${ }^{[14]}$; Lerher et $a .^{[21]}$ ), the system runs with random storage and retrieval policy. Under the policy, the retrieval transaction and storage transaction can be assigned to any storage position with the same probability.

- We assume that the equipment in C\&SBS/RS operates in dual-command cycles, i.e., a storage transaction and retrieval transaction in each cycle.

- The dwell point policy of cranes, RGVs, shuttles, and lifters follows the point-ofservice-completion (POSC);

- The transporters manage the transaction queue in the first-come, first-served (FCFS) discipline.

- One storage position contains one pallet or one tote. Each pallet or tote can contain many cases depending on the SKU package size but only hold one SKU type. 
- We assume that there is enough stock in $\mathrm{CBS} / \mathrm{RS}$ to satisfy replenishment, i.e., there is no replenish to $\mathrm{CBS} / \mathrm{RS}$ from outside

\subsection{Main notation}

The main notation of this study are as follows:

$\begin{array}{cl}N_{C, A}, N_{C, T}, N_{C, C}: & \text { Number of CBS/RS storage aisles, tiers and columns } \\ N_{S, A}, N_{S, T}, N_{S, C}: & \text { Number of SBS/RS storage aisles, tiers and columns } \\ u_{S, w}, u_{S, d}, u_{S, h}: & \text { Unit gross width, depth and height per storage position of SBS/RS } \\ u_{C, w}, u_{C, d}, u_{C, h}: & \text { Unit gross width, depth and height per storage position of CBS/RS } \\ N_{C, R}, N_{C, I, P}, N_{C, I, W}: & \text { Number of RGVs, I/O points and I/O workstations in the CBS/RS } \\ v v_{c r}, v a_{c r}: & \text { Vertical maximum velocity and acceleration/ deceleration of crane } \\ h v_{c r}, h a_{c r}: & \text { Horizontal maximum velocity and acceleration/deceleration of crane } \\ v_{R}, a_{R}: & \text { Maximum velocity and acceleration/ deceleration rate of RGV } \\ v_{l}, a_{l}: & \text { Maximum velocity and acceleration/ deceleration rate of the lifter } \\ v_{S}, a_{s}: & \text { Maximum velocity and acceleration/ deceleration rate of the shuttle } \\ t_{c r}, t_{l}, t_{s}, t_{R}: & \text { Fixed time required for the crane, lift, shuttle and RGV to load or unload the tote } \\ T_{c r}, T_{R}, T_{l}, T_{s}: & \text { Mean service time of crane, RGV, lift and shuttle } \\ T h_{C}, T h_{S}: & \text { Throughput of CBS/RS and SBS/RS } \\ Q_{p}, Q_{t}: & \text { Quantity of full pallet and tote (cases) } \\ \rho & \text { Proportion of high turnover SKU } \\ Q_{r, j} & \text { Quantity of } j \text { th SKU replenishment } \\ D_{j} & \text { Workload of } j \text { th SKU replenishment }\end{array}$

\subsection{Modelling the C\&SBS/RS}

\subsubsection{Analyzing throughput of CBS/RS}

Throughput of the CBS/RS represents the number of pallets that the system can retrieve per time unit. As in Marchet et al. ${ }^{[15]}$ research, throughput is defined by the bottleneck of the system (i.e., the throughput of the system equals to the throughput of bottlenecks), which is related to the rack configuration and mechanical properties.

Throughput of $\mathrm{CBS} / \mathrm{RS}$ is calculated as follows:

$$
\begin{gathered}
T H_{C}=\min \left\{\frac{N_{C, A}}{T_{c r}}, \frac{N_{C, R}}{T_{R}}\right\} \quad \text { (1) } \begin{array}{l}
\text { the assumption of random storage and retrieval } \\
\text { policy. }
\end{array} \\
T_{c r}=\frac{2}{N_{C, T} \times N_{C, C}} \times \sum_{i=1}^{N_{C, T} \times N_{C, C}} T_{c r}^{\mathrm{i}}(i)+\frac{1}{\left(N_{C, T} \times N_{C, C}\right)^{2}-\left(N_{C, T} \times N_{C, C}\right)} \times \sum_{i=1}^{N_{C, T} \times N_{C, C}} \sum_{\substack{j=1 \\
i \neq j}}^{N_{C, T} \times N_{C, C}} T_{c r}^{\mathrm{ii}}(i, j)+4 \times
\end{gathered}
$$

Where $T_{c r}$ and $T_{R}$ represent the average cycle time of each crane and $\mathrm{RGV}, \frac{N_{C, A}}{T_{c r}}$ and $\frac{N_{C, R}}{T_{R}}$ represent the throughput of all cranes and RGVs.

The average dual-command cycle time of cranes is divided into seven steps: i. pick up the pallet ai I/O point, ii. travel from I/O point to the storage destination position, iii. release the pallet, iv. Move to the retrieval destination position, v. pick up the pallet, vi. Return to the I/O point, vii. Release the pallet. Therefore $T_{c r}$ can be calculated by equation (2) according to 


$$
\begin{aligned}
& t_{c r}=\frac{2}{N_{C, T} \times N_{C, C}} \times \sum_{i=1}^{N_{C, T} \times N_{C, C}} \max \left\{T_{c r_{v}}^{\mathrm{i}}(i), T_{c r_{h}}^{\mathrm{i}}(i)\right\}+\frac{1}{\left(N_{C, T} \times N_{C, C}\right)^{2}-\left(N_{C, T} \times N_{C, C}\right)} \times \\
& \sum_{\substack{i=1 \\
N_{C, T} \times N_{C, C}}}^{N_{C=1} N_{C, T} \times N_{C, C}} \max \left\{T_{c r_{v}}^{\mathrm{ii}}(i, j), T_{c r_{h}}^{\mathrm{ii}}(i, j)\right\}+4 \times t_{c r}
\end{aligned}
$$

Where $T_{c r_{v}}{ }^{\mathrm{i}}(i)$ and $T_{c r_{h}}^{\mathrm{i}}(i)$ represent the travel time in the vertical and horizontal

directions from $\mathrm{I} / \mathrm{O}$ point to the destination storage position. $T_{c r_{v}}^{\mathrm{ii}}(i, j)$ and $T_{c r}^{\mathrm{ii}}(i, j)$ represent the travel time in the vertical and horizontal directions from a storage position to the destination retrieval position. The travel time is divided into two formulations depending on whether peak velocity is reached and calculated as follows:

$$
\begin{gathered}
T_{c r}{ }_{v}^{\mathrm{i}}(i)= \\
\left\{\begin{array}{c}
2 \times \frac{v v_{c r}}{v a_{c r}}+\frac{D_{v}(i)-\frac{v v_{c r}{ }^{2}}{v a_{c r}}}{v v_{c r}}, D_{v}(i)>\frac{v v_{c r}{ }^{2}}{v a_{c r}} \\
2 \times \sqrt{\frac{D_{v}(i)}{v a_{c r}}}, D_{v}(i) \leq \frac{v v_{c r}{ }^{2}}{v a_{c r}} \\
T_{c r}{ }_{h}^{\mathrm{i}}(i)= \\
2 \times \frac{h v_{c r}}{h a_{c r}}+\frac{D_{h}(i)-\frac{h v_{c r}{ }^{2}}{h a_{c r}}}{h v_{c r}}, D_{h}(i)>\frac{h v_{c r}^{2}}{h a_{c r}} \\
2 \times \sqrt{\frac{D_{h}(i)}{h a_{c r}}}, D_{h}(i) \leq \frac{h v_{c r}^{2}}{h a_{c r}}
\end{array}\right.
\end{gathered}
$$

Where $D_{v}(i)$ and $D_{h}(i)$ represent the vertical and horizontal travel distance of cranes:

$$
\begin{gathered}
D_{v}(i)=\left\lceil\frac{i-1}{N_{C, C}}\right\rfloor \times u_{C, h} \\
D_{h}(i)=\left(i-\left\lfloor\frac{i}{N_{C, C}}\right\rfloor \times N_{C, C}\right) \times u_{C, w} \\
T_{c r_{v}}^{\mathrm{ii}}(i, j) \quad \text { and } \quad T_{c r_{h}}^{\mathrm{ii}}(i, j) \quad \text { can be }
\end{gathered}
$$

calculated by:

$$
\begin{gathered}
T_{c r}^{\mathrm{ii}}(i, j)= \\
\left\{\begin{array}{c}
2 \times \frac{v v_{c r}}{v a_{c r}}+\frac{D_{v}(i, j)-\frac{v v_{c r}{ }^{2}}{v a_{c r}}}{v v_{c r}}, D_{v}(i, j)>\frac{v v_{c r}{ }^{2}}{v a_{c r}} \\
2 \times \sqrt{\frac{D_{v}(i, j)}{v a_{c r}}}, D_{v}(i, j) \leq \frac{v v_{c r}{ }^{2}}{v a_{c r}}
\end{array}\right.
\end{gathered}
$$

$$
\begin{gathered}
T_{c r}^{\mathrm{ii}}(i, j)= \\
\left\{\begin{array}{c}
2 \times \frac{h v_{c r}}{h a_{c r}}+\frac{D_{h}(i, j)-\frac{h v_{c r}{ }^{2}}{h a_{c r}}}{h v_{c r}}, D_{h}(i, j)>\frac{h v_{c r}{ }^{2}}{h a_{c r}} \\
2 \times \sqrt{\frac{D_{h}(i, j)}{h a_{c r}}}, D_{h}(i, j) \leq \frac{h v_{c r}{ }^{2}}{h a_{c r}}
\end{array}\right.
\end{gathered}
$$

Where $D_{v}(i, j)$ and $D_{h}(i, j)$ represent the vertical and horizontal travel distance of cranes:

$$
\begin{gathered}
D_{v}(i, j)=\left\lceil\frac{|i-j|}{N_{C, C}}\right\rfloor \times u_{C, h} \\
D_{h}(i, j)=\mid\left(i-\left\lfloor\frac{i}{N_{C, C}}\right\rfloor \times N_{C, C}\right)-(j- \\
\left.\left\lfloor\frac{j}{N_{C, C}}\right\rfloor \times N_{C, C}\right) \mid \times u_{C, w}
\end{gathered}
$$

The dual-command cycle of $\mathrm{RGV}$ is divided into $\frac{1}{2} \times N_{C, I, P} \times \frac{1}{2} \times N_{C, I, W}$ scenarios. The average cycle time $T_{R}$ is calculated as follows:

$$
\begin{array}{r}
T_{R}=\frac{1}{\frac{1}{2} \times N_{C, I, P} \times \frac{1}{2} \times N_{C, I, W}} \times \\
\sum_{i=1}^{\frac{1}{2} \times N_{C, I, P} \times \frac{1}{2} \times N_{C, I, W}} T_{R}(i)+2 \times t_{R}
\end{array}
$$

Where $T_{R}(i)$ represents the travel time in each scenario.

$$
T_{R}(i)=\left\{\begin{array}{c}
2 \times \frac{v_{R}}{a_{R}}+\frac{D(i)-\frac{v_{R}{ }^{2}}{a_{R}}}{v_{R}}, D(i)>\frac{v_{R}^{2}}{a_{R}} \\
2 \times \sqrt{\frac{D(i)}{a_{R}}}, D(i) \leq \frac{v_{R}^{2}}{a_{R}}
\end{array}\right.
$$

\subsubsection{Analyzing the throughput of SBS/RS}

As in CBS/RS case, the throughput of SBS/RS is a function of bottlenecks due to the use of different resources (i.e., shuttles and lifters), which represents the number of totes that the system can retrieval per time unit. 
Throughput of SBS/RS is calculated as follows:

$$
T h_{S}=\min \left\{\frac{N_{S, T}}{T_{S}}, \frac{N_{S, A}}{T_{l}}\right\}
$$

Where $T_{S}$ and $T_{l}$ represent the average cycle time of each crane and RGV, $\frac{N_{S, T}}{T_{S}}$ and $\frac{N_{S, A}}{T_{l}}$ represent the throughput of all cranes and RGVs.

Considering the assumption of the dualcommand cycle with seven steps, random storage and retrieval policy and acceleration/deceleration effect. $T_{S}$ can be calculated by follows:

$$
\begin{aligned}
& T_{S}=\frac{2}{N_{S, C}} \times \sum_{i=1}^{N_{S, C}} T_{S}(i)+\frac{1}{N_{S, C}{ }^{2}-N_{S, C}} \times \\
& \sum_{i=1}^{N_{S, C}} \sum_{\substack{j=1 \\
j \neq i}}^{N_{S, C}} T_{S}(i, j)+4 \times t_{s}
\end{aligned}
$$

Where $T_{S}(i)$ and $T_{S}(i, j)$ represent the travel time and can be calculated as follows:

$$
\begin{aligned}
& T_{S}(i)= \\
& \left\{\begin{array}{c}
2 \times \frac{v_{s}}{a_{s}}+\frac{i \times u_{S, w}-\frac{v_{s}{ }^{2}}{a_{s}}}{v_{s}}, i \times u_{S, w}>\frac{v_{s}^{2}}{a_{s}} \\
2 \times \sqrt{\frac{i \times u_{S, w}}{a_{s}}}, i \times u_{S, w} \leq \frac{v_{s}^{2}}{a_{s}}
\end{array}\right. \\
& T_{s}(i, j)= \\
& \left\{\begin{array}{c}
2 \times \frac{v_{s}}{a_{s}}+\frac{|i-j| \times u_{S, w}-\frac{v_{s}{ }^{2}}{a_{s}}}{v_{s}},|i-j| \times u_{S, w}>\frac{v_{s}^{2}}{a_{s}} \\
2 \times \sqrt{\frac{|i-j| \times u_{S, w}}{a_{s}}},|i-j| \times u_{S, w} \leq \frac{v_{s}^{2}}{a_{s}}
\end{array}\right.
\end{aligned}
$$

The POSC assumption stipulates that the output lifter dwells at the first tier when the transaction is completed and the input lifter dwells at destination tier related to the storage transaction. The movement of the output lifter includes four steps: (i) travel from the first tier to the destination tier. (ii) pick up the tote. (iii) return to the first tier. (iv) release the tote. The input lifter: (i) moves to the first tier. (ii) picks up the tote. (iii) travel to destination tier. (iv) release the tote. When the destination tier is the first tier, the lifter only provides load and unload the tote movement. Therefore $T_{l}$ is calculated by:

$$
T_{l}=\frac{1}{N_{S, T}} \times \sum_{i=1}^{N_{S, T}} 2 \times T_{l}(i)+2 \times t_{l}
$$

Where $T_{l}(i)$ represents the travel time and is divided into two formulations depending on whether peak velocity is reached.

$$
\begin{gathered}
T_{l}(i)= \\
\left\{\begin{array}{c}
2 \times \frac{v_{l}}{a_{l}}+\frac{(i-1) \times u_{S, w}-\frac{v_{l}^{2}}{a_{l}}}{v_{l}},(i-1) \times u_{S, w}>\frac{v_{l}^{2}}{a_{l}} \\
2 \times \sqrt{\frac{(i-1) \times u_{S, w}}{a_{l}}},(i-1) \times u_{S, w} \leq \frac{v_{l}^{2}}{a_{l}}
\end{array}\right.
\end{gathered}
$$

\section{Replenishment strategy}

\subsection{Order structure}

We define the order matrix to descript the order structure according to SHEN ${ }^{[19]}$. The order matrix is combined by all orders in one wave, rows of order matrix represent the order and columns represent the SKU as shown in Fig 3. We divide the orders into $I \times J$ grids, where $I$ indicates the total number of orders in one wave and $J$ indicates the total number of SKU. Therefore, the order matrix is defined as follows:

$$
O=\left(q_{i j}\right)_{I \times J}
$$

Where, $i \in\{1,2, \cdots, I\}$ represents the $i$ th order $j \in\{1,2, \cdots, J\}$ represents the $j$ th SKU $q_{i j}$ represents the requested quantity of the $j$ th SKU in the $i$ th order 


\begin{tabular}{|c|c|c|c|c|c|c|c|c|c|}
\hline & & $\begin{array}{c}s k u_{1} \\
\mathrm{y}_{1}\end{array}$ & $\begin{array}{c}s k u_{2} \\
\mathrm{y}_{2}\end{array}$ & $\begin{array}{c}s k u_{3} \\
\mathrm{y}_{3}\end{array}$ & $\begin{array}{c}\mathrm{sku}_{4} \\
\mathrm{y}_{4}\end{array}$ & $\begin{array}{c}s k u_{5} \\
\mathrm{y}_{5}\end{array}$ & $\begin{array}{l}\cdots \\
\cdots\end{array}$ & $\begin{array}{c}s k u_{j} \\
\mathrm{y}_{j}\end{array}$ & $\begin{array}{cc}\cdots & s k u_{J} \\
\cdots & \mathrm{y}_{J}\end{array}$ \\
\hline order $_{1}$ & $\mathrm{x}_{1}$ & $q_{(1,1)}$ & $q_{(1,2)}$ & $q_{(1,3)}$ & $q_{(1,4)}$ & $q_{(1,5)}$ & $\cdots$ & $q_{(1, j)}$ & $\cdots \quad q_{(1 J)}$ \\
\hline order $_{2}$ & $x_{2}$ & $q_{(2,1)}$ & $q_{(2,2)}$ & $q_{(2,3)}$ & $q_{(2,4)}$ & $q_{(2,5)}$ & $\cdots$ & $q_{(2, j)}$ & $\cdots \quad q_{(2 J)}$ \\
\hline $\mathrm{order}_{3}$ & $x_{3}$ & $q_{(3,1)}$ & $q_{(3,2)}$ & $q_{(3,3)}$ & $q_{(3,4)}$ & $q_{(3,5)}$ & $\cdots$ & $q_{(3, i)}$ & $\cdots \quad q_{(3 J)}$ \\
\hline order $_{4}$ & $\mathrm{x}_{4}$ & $q_{(4,1)}$ & $q_{(4,2)}$ & $q_{(4,3)}$ & $q_{(4,4)}$ & $q_{(4,5)}$ & $\cdots$ & $q_{(4, j)}$ & $\cdots \quad q_{(4 J)}$ \\
\hline$\cdots$ & $\cdots$ & $\cdots$ & $\cdots$ & $\cdots$ & $\cdots$ & $\cdots$ & $\cdots$ & $\cdots$ & $\cdots$ \\
\hline order $_{i}$ & $\mathrm{x}_{i}$ & $q_{(i, 1)}$ & $q_{(i, 2)}$ & $q_{(i, 3)}$ & $q_{(i, 4)}$ & $q_{(i, 5)}$ & $\cdots$ & $q_{(i, j)}$ & $\cdots \quad q_{(i, J)}$ \\
\hline$\cdots$ & $\cdots$ & $\cdots$ & $\cdots$ & $\cdots$ & $\cdots$ & $\cdots$ & $\cdots$ & $\cdots$ & $\cdots$ \\
\hline order $_{I}$ & $\mathrm{x}_{I}$ & $q_{(I, 1)}$ & $q_{(I, 2)}$ & $q_{(I, 3)}$ & $q_{(I, 4)}$ & $q_{(I, 5)}$ & $\cdots$ & $q_{(I, j)}$ & $\cdots \quad q_{(I, J)}$ \\
\hline
\end{tabular}

Figure 3. Definition of order matrix

The total request quantity of the $j$ th SKU in this wave is:

$$
Q_{j}=\sum_{i=1}^{I} q_{i j}
$$

The request frequency matrix is defined by the following:

$$
A=\left(a_{i j}\right)_{I \times J}
$$

Where, $i \in\{1,2, \cdots, I\}$ represents the $i$ th order, $j \in\{1,2, \cdots, J\}$ represents the $j$ th SKU, $a_{i j}$ represents whether the $j$ th SKU is requested in the $i$ th order.

$$
a_{i j}= \begin{cases}1 & q_{i j}>0 \\ 0 & q_{i j}=0\end{cases}
$$

Therefore, the total request frequency of the $j$ th SKU in this wave is:

$$
A_{j}=\sum_{i=1}^{I} a_{i j}
$$

The following is several indicators to reflect the order structure:

i. The size of wave $\alpha$ represents the total number of orders and equals to $I$;

ii. The density of order $\beta$ represents the number range of request SKU in one order and is calculated by:

$$
A_{i}=\sum_{j=1}^{J} a_{i j}
$$

iii. The strength of order $\gamma$ represents the request quantity rage of one SKU in each order and equals to $q_{i j}$

Then the order matrix can be represented by the above three indicators:

$$
O=f(\alpha, \beta, \gamma)
$$

\subsection{Replenishment strategy}

In C\&SBS/RS, SBS/RS only processes cases and items picking as an aid which has limited number storage position. Therefore, it becomes unrealistic that all SKU store in SBS/RS. However, if only the requested SKUs is allowed to be stored in SBS/RS, that inevitably increase the workload of equipment (e.g., crane, shuttle, RGV and lifter) in the wave cycle. If all SKUs are stored in SBS/RS, maybe it can reduce the workload of equipment, but the limited storage position in SBS/RS is not enough to sport this strategy. This paper aims to find the happy medium for replenishment considering the workload and storage position. The warehouse management computer creates replenishment tasks according to the following four steps:

Step1: Processing orders. when orders of one wave arrive, the computer divides orders sequentially according to the principle that the full pallet picking requests CBS/RS while the cases and items picking requests SBS/RS. Then the cases and items picking is merging separately by SKU type to calculate the total picking quantity for each SKU as equation (20) illustrate.

Step2: Inventory matching. similar to the form of the order matrix, we define the inventory matrix by:

$$
H=\left[h_{1}, h_{2}, \cdots, h_{j}, \cdots, h_{J}\right]
$$

Where, $j \in\{1,2, \cdots, J\}$ represents the $j$ th $\mathrm{SKU}, h_{j}$ represents the stock quantity of the $j$ th SKU

The number of occupied storage positions can be calculated by: 


$$
L_{o}=\sum_{j=1}^{J}\left\lceil\frac{h_{j}}{Q_{t, j}}\right\rceil
$$

Step3: SKU main-data matching. SKU main date includes the full quantity of a tote, the full quantity of a pallet and the SKU type. The SKU type is divided according to the turnover rate for a while (e.g., one year, one month, one quarter). The SKU type matrix is defined by the following:

$$
S=\left[s_{1}, s_{2}, \cdots, s_{j}, \cdots, s_{J}\right]
$$

Where, $j \in\{1,2, \cdots, J\}$ represents the $j$ th $\mathrm{SKU}, s_{j}$ represents whether the $j$ th SKU belongs to the high turnover type.

$$
s_{j}=
$$

(1 jth SKU belongs to the high turnover type $\left\{\begin{array}{l}0 \\ 0 \text { th SKU belongs to the low turnover type }\end{array}\right.$

Therefore, the proportion of high turnover type is calculated by:

$$
\rho=\frac{\sum_{j=1}^{J} S_{j}}{J}
$$

When $s_{j}=1, j$ th SKU belongs to the high turnover type and should be replenished overmuch. $s_{j}=0$, jth SKU belongs to the low

$$
\begin{gathered}
D_{C, j}=\left\{\begin{array}{lr}
\left\lceil\frac{\max \left(\sum_{i=1}^{I} q_{(i, j)}-h_{j}, 0\right)}{Q_{p, j}}\right\rceil & s_{j}=1 \\
1+\left\lceil\frac{\sum_{i=1}^{I} q_{(i, j)}-h_{j}}{Q_{p, j}}\right\rceil & s_{j}=0,\left(\sum_{i=1}^{I} q_{(i, j)}-h_{j}\right) \bmod Q_{p, j}>0 \\
\frac{\sum_{i=1}^{I} q_{(i, j)}-h_{j}}{Q_{p, j}} & s_{j}=0,\left(\sum_{i=1}^{I} q_{(i, j)}-h_{j}\right) \bmod Q_{p, j}=0 \\
0 & s_{j}=0,\left(\sum_{i=1}^{I} q_{(i, j)}-h_{j}\right) \bmod Q_{p, j}<0
\end{array}\right. \\
D_{S, j}= \begin{cases}2 \times\left\lceil\left\lceil\frac{\max \left(\sum_{i=1}^{I} q_{(i, j)}-h_{j}, 0\right)}{Q_{p, j}}\right\rceil \times \frac{Q_{p, j}}{Q_{t, j}}\right\rceil & s_{j}=1 \\
2 \times\left\lceil\frac{\max \left(\sum_{i=1}^{I} q_{(i, j)}-h_{j, 0}\right)}{Q_{p, j}}\right\rceil & s_{j}=0\end{cases}
\end{gathered}
$$

\subsection{Modelling replenishment}

During processing orders in each wave, first replenishing and then picking, the minimum replenishment time can release more picking time for outbound in C\&SBS/RS considering limited picking time of one wave. Hence it is obvious that the optimal object is the minimum replenishment time. turnover type and should be replenished according to demand. The quantity of replenishment is defined by:

$$
\begin{gathered}
Q_{r, j}= \\
\begin{cases}\left\lceil\frac{\max \left(\sum_{i=1}^{I} q_{(i, j)}-h_{j}, 0\right)}{Q_{p, j}}\right\rceil \times Q_{p, j} & s_{j}=1 \\
\max \left(\sum_{i=1}^{I} q_{(i, j)}-h_{j}, 0\right) & s_{j}=0\end{cases}
\end{gathered}
$$

Step4: Replenishment tasks. warehouse management computer creates replenishment tasks according to the quantity of replenishment $Q_{r, j}$. In $\mathrm{C} \& \mathrm{SBS} / \mathrm{RS}$, the replenishment task includes pallet retrieval and storage transaction in $\mathrm{CBS} / \mathrm{RS}$, the empty totes retrieval transaction and full totes storage transaction in SBS/RS as Fig 2 illustrates. Hence the workload of replenishment (i.e., the number of replenishment task) can be calculated as follows:

$$
\sum_{j=1}^{J} D_{j}=\sum_{j=1}^{J} D_{C, j}+D_{s, j}
$$

$D_{C, j}$ and $D_{s, j}$ represent the workload of replenishment in $\mathrm{CBS} / \mathrm{RS}$ and $\mathrm{SBS} / \mathrm{RS}$ respectively and can be calculated by using equation (33) and (34).$$
\min \left(\max \left(\sum_{j=1}^{J} \frac{D_{C, j}}{T H_{C}}, \sum_{j=1}^{J} \frac{D_{s, j}}{T H_{S}}\right)\right)
$$

Constraints:

$$
\begin{gathered}
\sum_{j=1}^{J} D_{C, j}<T \times T H_{C} \\
\sum_{j=1}^{J} D_{S, j}<T \times T H_{S} \\
\sum_{j=1}^{J}\left\lceil\frac{Q_{r, j}+h_{j}}{Q_{t, j}}\right\rceil<2 \times N_{S, A} \times N_{S, T} \times N_{S, C}
\end{gathered}
$$

$$
Q_{t, j}<Q_{p, j}
$$




$$
\sum_{j=1}^{J} s_{j} \leq J \quad s_{j}=\{0,1\}
$$

Equation (35) defines the objective to minimize the replenishment time. The constraint (36) and (37) is to ensure there is enough equipment capacity to fulfil those replenishment tasks. Constraint (38) limits the storage positions and constraint (39) is to describe that the quantity of full totes is less than full pallets. Constraint (40) illustrates the relationship between SKU type matrix and order matrix.

\section{Experimental study}

Equation (25) illustrates the order matrix includes three main factors: The size of wave $\alpha$, the density of order $\beta$ and the strength of order $\gamma$. Considering the order structure suitability, we compare the workload of $\mathrm{CBS} / \mathrm{RS}$ and SBS/RS, the number of used storage position and the replenishment time. Table 1 sets the different order structure factors $(\gamma, \beta, \alpha)$ and the proportion of high turnover SKU $\rho$.

Table 1. experimental parameters

\begin{tabular}{|c|c|c|c|c|}
\hline$\gamma$ & $\beta$ & $\alpha$ & \multicolumn{2}{|c|}{$\rho$} \\
\hline 1 & 10: 10: 100 & 10: $10: 100$ & 1: 10 & $100 \%$ \\
\hline $1 \sim 10$ & 10: $10: 100$ & 10: $10: 100$ & 1: 10 & $100 \%$ \\
\hline $1 \sim 50$ & 10: $10: 100$ & 10: $10: 100$ & 1: 10 & $100 \%$ \\
\hline \multicolumn{5}{|c|}{ Table 2. parameters of the C\&SBS/RS } \\
\hline Parameters & & & Notation & Value \\
\hline \multicolumn{3}{|c|}{ Number of CBS/RS storage aisles, tiers and columns } & $N_{C, A}, N_{C, T}, N_{C, C}$ & $2,5,60$ \\
\hline \multicolumn{3}{|c|}{ Number of SBS/RS storage aisles, tiers and columns } & $N_{S, A}, N_{S, T}, N_{S, C}$ & $1,15,140$ \\
\hline \multicolumn{3}{|c|}{ Unit width, depth and height per storage position of SBS/RS(m) } & $u_{S, w}, u_{S, d}, u_{S, h}$ & $0.5,0.7,0.5$ \\
\hline \multicolumn{3}{|c|}{ Unit width, depth and height per storage position of CBS/RS(m) } & $u_{C, w}, u_{C, d}, u_{C, h}$ & $1.16,1.2,1.7$ \\
\hline \multicolumn{3}{|c|}{ Vertical maximum velocity and horizontal maximum velocity of crane $(\mathrm{m} / \mathrm{s})$} & $v v_{c r}, h v_{c r}$ & 1,3 \\
\hline \multicolumn{3}{|c|}{ Vertical and horizontal acceleration/deceleration of crane $\left(\mathrm{m} / \mathrm{s}^{2}\right)$} & $v a_{c r}, h a_{c r}$ & $0.5,0.6$ \\
\hline \multicolumn{3}{|c|}{ Maximum Velocity of RGV, shuttle, lifter(m/s) } & $v_{R}, v_{s}, v_{l}$ & $2,3,3$ \\
\hline \multicolumn{3}{|c|}{ Acceleration/ deceleration rate of $1 \mathrm{RGV}$, shuttle, $\operatorname{lifter}\left(\mathrm{m} / \mathrm{s}^{2}\right)$} & $a_{R}, a_{s}, a_{l}$ & $1.5,1,3$ \\
\hline \multicolumn{3}{|c|}{ Number of RGVs, I/O points and I/O workstations in the CBS/RS } & $N_{C, R}, N_{C, I, P}, N_{C, I, W}$ & $1,2,2$ \\
\hline \multicolumn{3}{|c|}{$\begin{array}{l}\text { Fixed time required for the crane, lift, shuttle and RGV to load or unload the } \\
\text { tote }\end{array}$} & $t_{c r}, t_{l}, t_{s}, t_{R}$ & $10,5,4,1$ \\
\hline
\end{tabular}

The order structure has a greater impact on the formulation of replenishment strategies (e.g., what is the proportion of high turnover SKU? How much to set the size of a wave?), which directly affects the operational efficiency of the distribution centre. Without loss of generality, we set 10 groups experiments for each scenario, each group contains 100 waves. The strength of order $\gamma$ represents the requested quantity of SKU in each order, we set fixed value 1, uniform distribution $\mathrm{U}[1,10]$ and $\mathrm{U}[1,50]$. The system parameters come from Table 2 . 


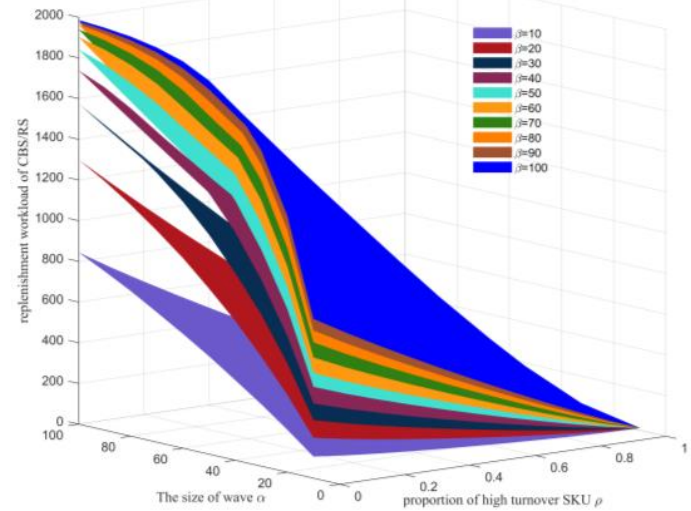

a.replenishiment workload of CBS/RS

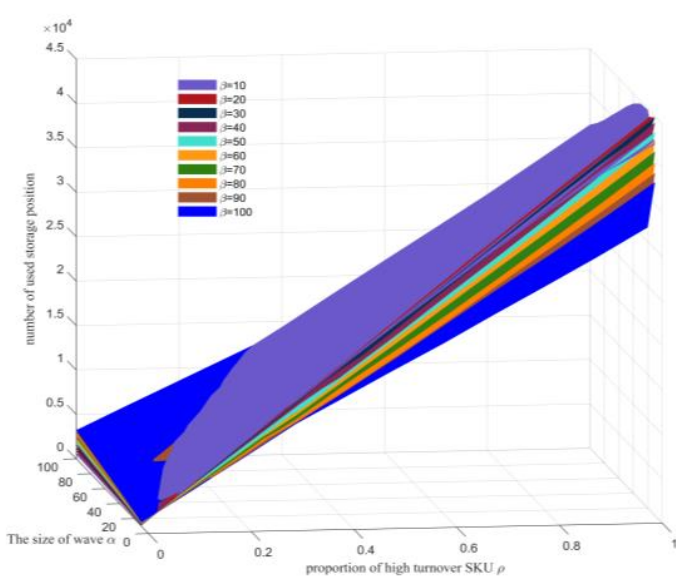

c.number of used storage position

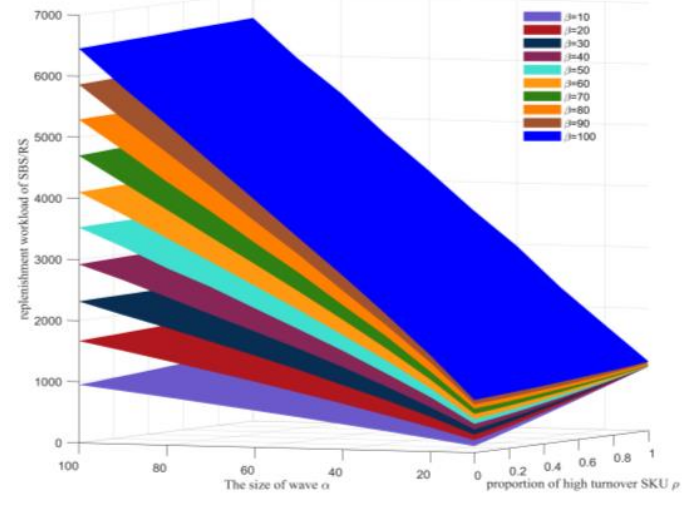

b.replenishiment workload of SBS/RS

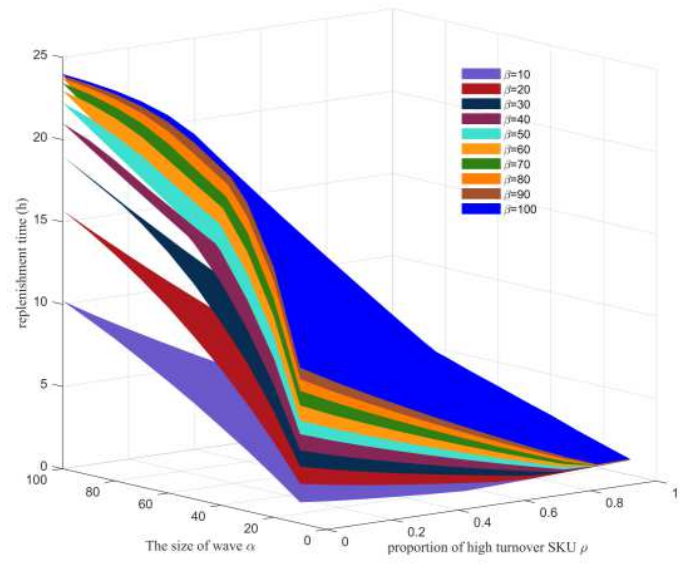

d.replenishment time(h)

Figure 4. effect of $\gamma=1$

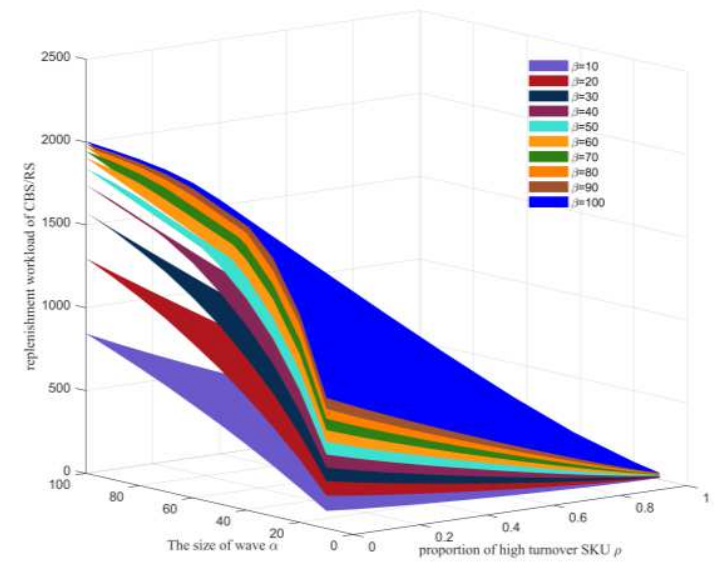

a.replenishiment workload of CBS/RS

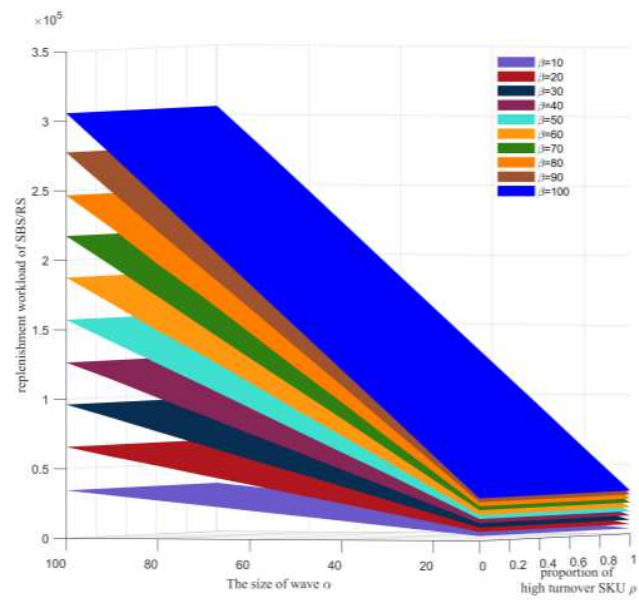

b.replenishiment workload of SBS/RS 


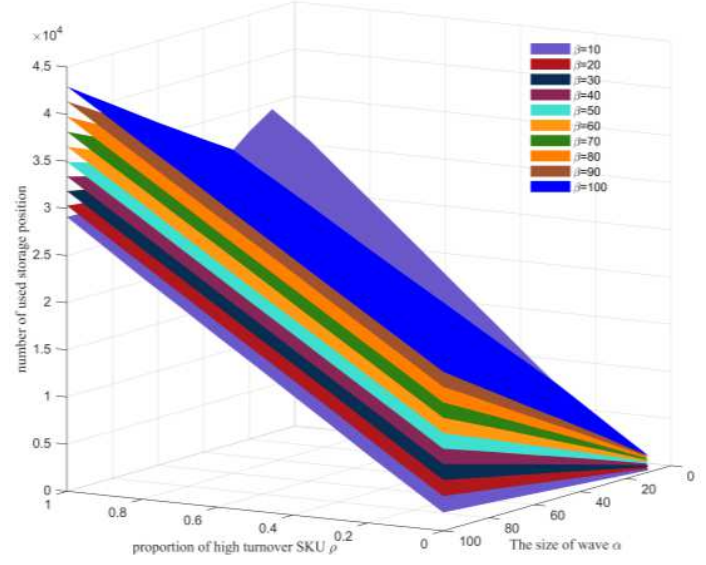

c.number of used storage position

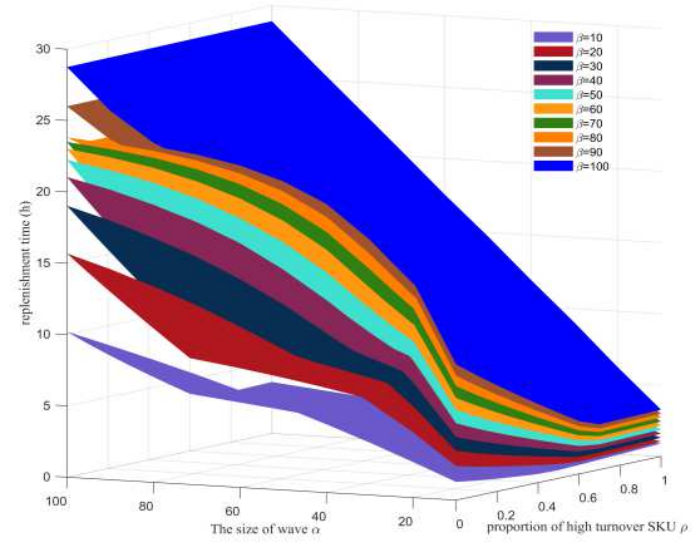

d.replenishment time(h)

Figure 5. effect of $\gamma=\mathrm{U}[1,10]$

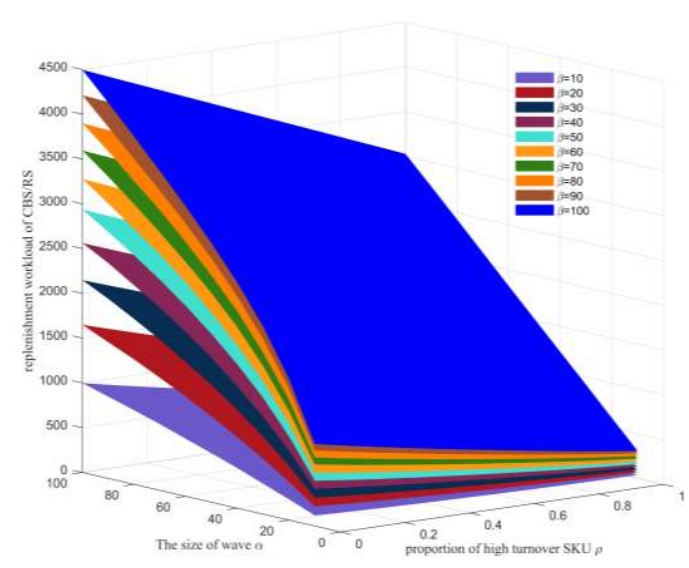

a.replenishiment workload of CBS/RS

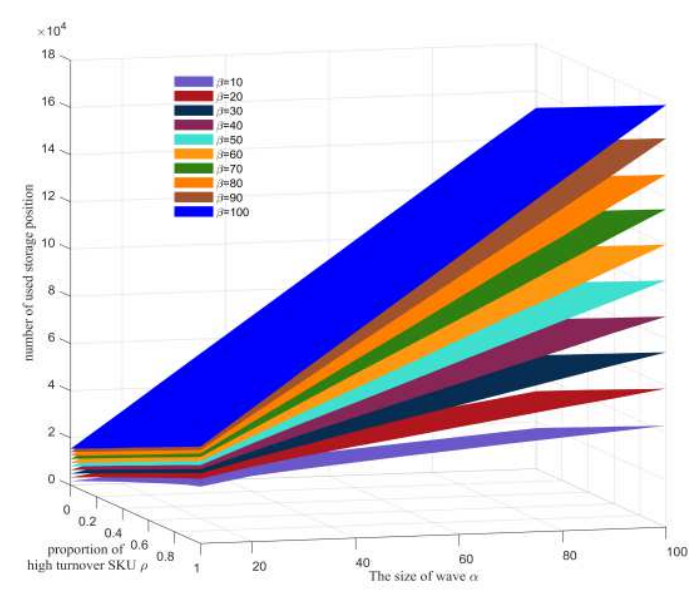

c.number of used storage position

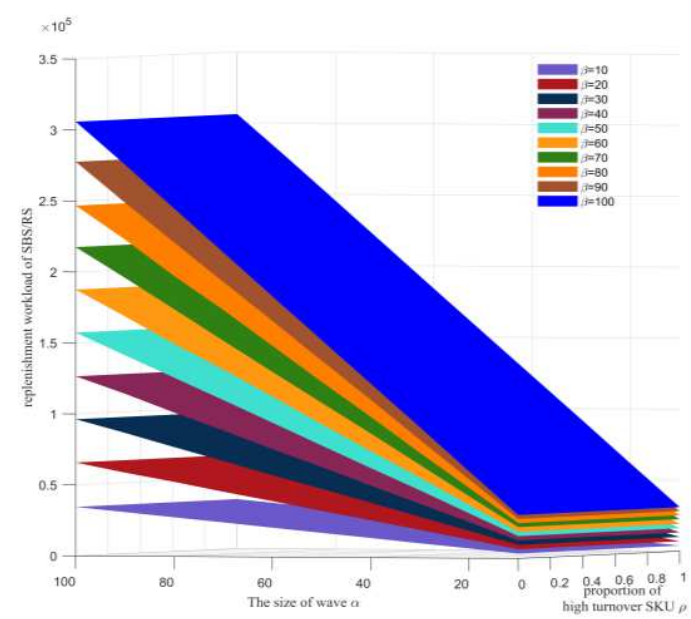

b.replenishiment workload of SBS/RS

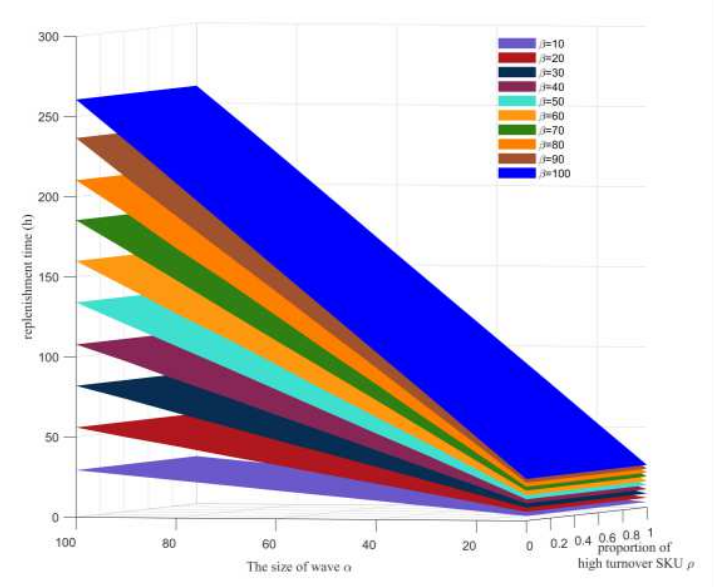

d.replenishment time $(\mathrm{h})$

Figure 6. effect of $\gamma=\mathrm{U}[1,50]$ 
The effect of order strength $\gamma$ is shown in Fig 4 Fig 6. The following observations on the replenishment transaction of C\&SBS/RS can be made based on these results:

(1). For replenishment workload of CBS/RS, as the number of high turnover SKU increases, the replenishment workload of $\mathrm{CBS} / \mathrm{RS}$ decreases; as the wave size increases, the extent of reduction becomes larger; as the wave size decreases, the replenishment workload of $\mathrm{CBS} / \mathrm{RS}$ decreases; as the number of high turnover SKU increases, the extent of reduction becomes smaller; as the order strength increases, the replenishment workload of $\mathrm{CBS} / \mathrm{RS}$ increases, whose extent of reduction decreases due to the decrease of the wave size; the extent of reduction of the replenishment workload of CBS/RS decreases with result of increasing of the number of high turnover SKU; as the order density increases, the replenishment workload of CBS/RS increases; when the order strength is small, the extent of reduction of the replenishment workload of CBS/RS increases due to the decrease in wave size, the extent of reduction of the replenishment workload of $\mathrm{CBS} / \mathrm{RS}$ increases with result of increasing of the number of high turnover SKU; when the order intensity is larger, the extent of reduction of the replenishment workload of CBS/RS decreases due to the decrease in wave size, the extent of reduction of the replenishment workload of $\mathrm{CBS} / \mathrm{RS}$ increases with result of increasing of the number of high turnover SKU.

(2). For replenishment workload of SBS/RS, as the number of high turnover SKU increases, the replenishment workload of SBS/RS has increased slightly, with little change overall; as the wave size decreases, the replenishment workload of SBS/RS decreases; as the order strength increases, the replenishment workload of SBS/RS increases, whose extent of reduction increases due to the decrease of the wave size; as the order density increases, the replenishment workload of SBS/RS increases; when the order strength and density are small, the extent of reduction of the replenishment workload of SBS/RS increases due to the number of high turnover SKU increases; conversely, the extent of reduction of the replenishment workload of SBS/RS decreases with the result of increasing of the number of high turnover SKU in a bigger order strength and density scenario.

(3). For the number of used storage position, as the number of high turnover SKU increases, the number of used storage position increases, whose extent of reduction decreases due to the order size increases; as the wave size decreases, the number of used storage position decreases, whose extent of reduction is almost independent of the wave size; as the order strength increases, the number of used storage position increases, whose extent of reduction increases due to the decrease of the wave size and decreases with the result of increasing of the number of high turnover SKUs; as the order density increases, the number of used storage position increases, whose extent of increase decreases.

(4). For the replenishment time, the replenishment time changes slightly when the order density is smaller. Conversely, if the order density increases, the number of high turnover SKU has a significant impact on the replenishment time, while the size of the wave does not. The result shows that as the increase of order strength, the changing trend of replenishment time is more and more tended to the changing trend of replenishment workload of SBS/RS, because of the replenishment time of 
$\mathrm{SBS} / \mathrm{RS}$ is more than it in CBS/RS.

\section{Conclusions}

We introduce a new automatic warehouse sorting system, i.e., C\&SBS/RS, and mainly study the system's replenishment strategy. The throughput model is established by analyzing the working process and the system structure. Then the order matrix is established to study the influence of order structure on replenishment strategy. In the experiment study, we analyze the impact of order size and order density on relevant parameters (e.g., the wave size and the proportion of high turnover SKU) in replenishment strategy. The warehouse operation manager can reduce the wave size and increase the proportion of high turnover SKU to minimize the replenishment time, which can increase the picking throughput of the system.

In additionally, the order structure can be explored in the future. Some rules and indicators can be described by order density, order strength, order size and other parameters to guide the determination of relevant parameters of the replenishment strategy.

\section{Reference:}

[1]. Azadeh K, De Koster R, Roya D. Robotized and Automated Warehouse Systems: Review and Recent Developments[J]. Transportation Science. 2019, 53(4): 917-945.

[2]. Hausman W H, Schwarz L B, Graves S C. Optimal storage assignment in automatic warehousing systems [J]. Management Science. 1976, 22(6): 629-638

[3]. Bozer Y A, White J A. Design and Performance Models for End-of-Aisle Order Picking Systems[J]. Management Science. 1990(No.7): 852-866.

[4]. De Koster R B M, Le-Duc T, Yugang Y. Optimal storage rack design for a 3-dimensional compact
AS/RS[J]. International Journal of Production Research. 2008(No.6): 1495-1514.

[5]. Yu Y, De Koster M B M. Designing an optimal turnover-based storage rack for a $3 \mathrm{D}$ compact automated storage and retrieval system[J]. International Journal of Production Research. 2009(No.6): 1551-1571

[6]. Roodbergen K J, Vis I F. A survey of literature on automated storage and retrieval systems $[\mathrm{J}]$. European Journal of Operational Research. 2009(No.2): 343-362.

[7]. Malmborg C J M R. Design optimization models for storage and retrieval systems using rail guided vehicles[J]. Applied Mathematical Modelling. 2003(NO.12): 929-941.

[8]. Malmborg C J. Interleaving dynamics in autonomous vehicle storage and retrieval systems[J]. International Journal of Production Research. 2003(NO.5): 1057-1069.

[9]. Malmborg C J. Conceptualizing tools for autonomous vehicle storage and retrieval systems.[J]. International Journal of Production Research. 2002(No.8): 1807-1822.

[10]. Fukunari M, Malmborg C J. A network queuing approach for evaluation of performance measures in autonomous vehicle storage and retrieval systems[J]. European Journal of Operational Research. 2009(No.1): 152-167.

[11]. Roy D, Krishnamurthy A, Heragu S S, et al. Performance analysis and design trade-offs in warehouses with autonomous vehicle technology[J]. IIE Transactions. 2012(No.12): 1045-1060.

[12]. Roy D, Krishnamurthy A, Heragu S S, et al. Blocking effects in warehouse systems with autonomous vehicles [J]. IEEE Transactions on Automation Science and Engineering. 2014(No.2): 439-451.

[13]. Ekren B Y, Heragu S S, Krishnamurthy A, et al. An Approximate Solution for Semi-Open Queueing Network Model of an Autonomous Vehicle Storage and Retrieval System[J]. IEEE Transactions on Automation Science and Engineering. 2013(No.1): 205-215. 
[14]. Ekren B Y, Heragu S S, Krishnamurthy A, et al. Matrix-geometric solution for semi-open queuing network model of autonomous vehicle storage and retrieval system.[J]. Computers and Industrial Engineering. 2014: 78-86.

[15]. Marchet G, Melacini M, Perotti S, et al. Development of a framework for the design of autonomous vehicle storage and retrieval systems[J]. International Journal of Production Research. 2013, 51(14): 4365-4387.

[16]. Wang Y, Mou S, Wu Y. Storage assignment optimization in a multi-tier shuttle warehousing system[J]. Chinese Journal of Mechanical Engineering. 2016, 29(2): 421-429.

[17]. Zou B, Xu X, Yale Gong Y, et al. Modeling parallel movement of lifts and vehicles in tiercaptive vehicle-based warehousing systems[J]. European Journal of Operational Research. 2016, 254(1): 51-67.

[18]. Tappia E, Roy D, Melacini M, et al. Integrated storage-order picking systems: Technology, performance models, and design insights[J]. European Journal of Operational Research. 2019, 274(3): 947-965

[19]. SHEN C.P., WU Y.H., ZHOU C. Selecting between Sequential Zoning and Simultaneous Zoning for Picker-to-parts Order Picking System Based on Order Cluster and Genetic Algorithm[J]. Chinese Journal of Mechanical Engineering. 2011, 24(5): 820-828.

[20]. WANG Y.Y., ZHOU Y.Q., SHEN C.P., WU Y.H. Applicability selection method of two parts-topicker order picking systems[J]. Chinese Journal of Mechanical Engineering.2015, 51(04):206212.

[21]. Lerher T, Ekren B Y, Dukic G, et al. Travel time model for shuttle-based storage and retrieval systems[J]. The International Journal of Advanced Manufacturing Technology. 2015, 78(9-12): 1705-1725.

\section{Biographical notes}

MA Wenkai, born in 1991, is currently a $\mathrm{PhD}$ candidate at school of control science and engineering, Shandong University, China. His research interests include optimization of automated warehouse system in distribution centres, simulation of order picking system.

E-mail: kevin.ma@mail.sdu.edu.cn

WANG Yanyan, born in 1978, is currently a professor at Shandong University, China. She received her $\mathrm{PhD}$ degree from Shandong University, China in 2012. Her research interests include the optimization of automated order picking and storage systems in logistics distribution.

E-mail: 1978 wyy@163.com

HU Jinchang, born in 1992, is currently a $\mathrm{PhD}$ candidate at school of control science and engineering, Shandong University, China. His research interests include the optimization of automated order picking and storage systems in logistics distribution

E-mail: hooke.1122@,mail.sdu.edu.cn

WU Yaohua, born in 1963, is currently a professor at Shandong University, China. $\mathrm{He}$ received his $\mathrm{PhD}$ degree from Tsinghua University, China, in 1996. His main research interests are in the field of facility planning. E-mail: yaohua.wu@sdu.edu.cn

\section{Appendix:}

When the replenishment transaction arrives, CBS/RS processes the pallet outbound and pallet inbound, while SBS/RS processes the empty tote outbound and tote inbound. The flowchart is shown in Fig A.1 A.4. 


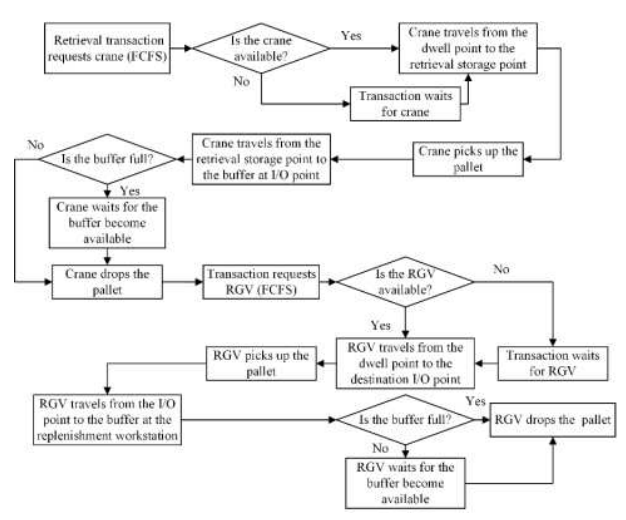

Figure A.1. Pallet outbound in CBS/RS

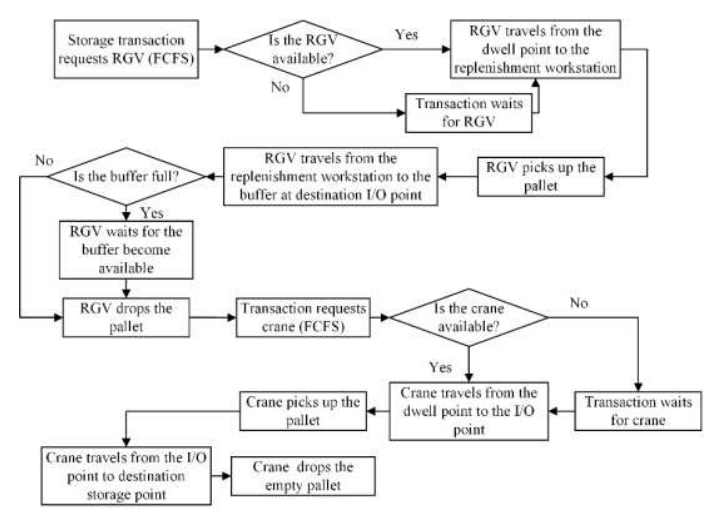

Figure A.2. Pallet inbound in CBS/RS

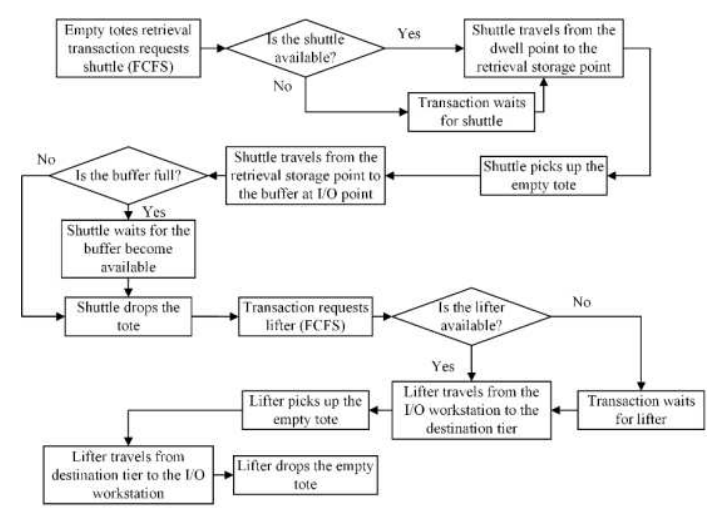

Figure A.3. Empty tote outbound in SBS/RS

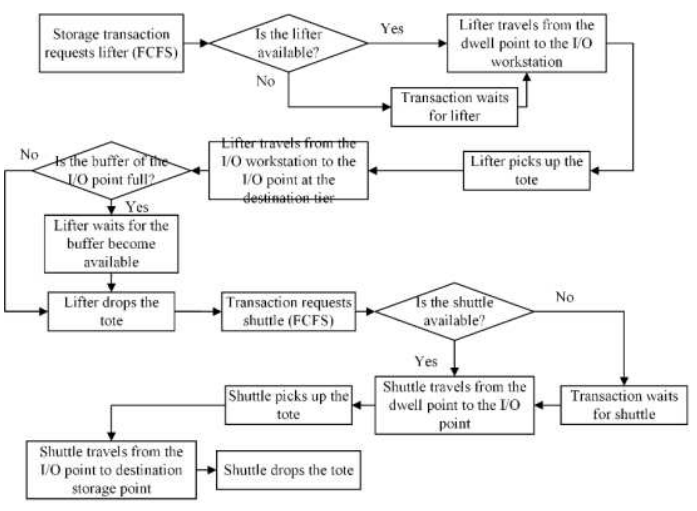

Figure A.4. Tote inbound in SBS/RS 
Figures

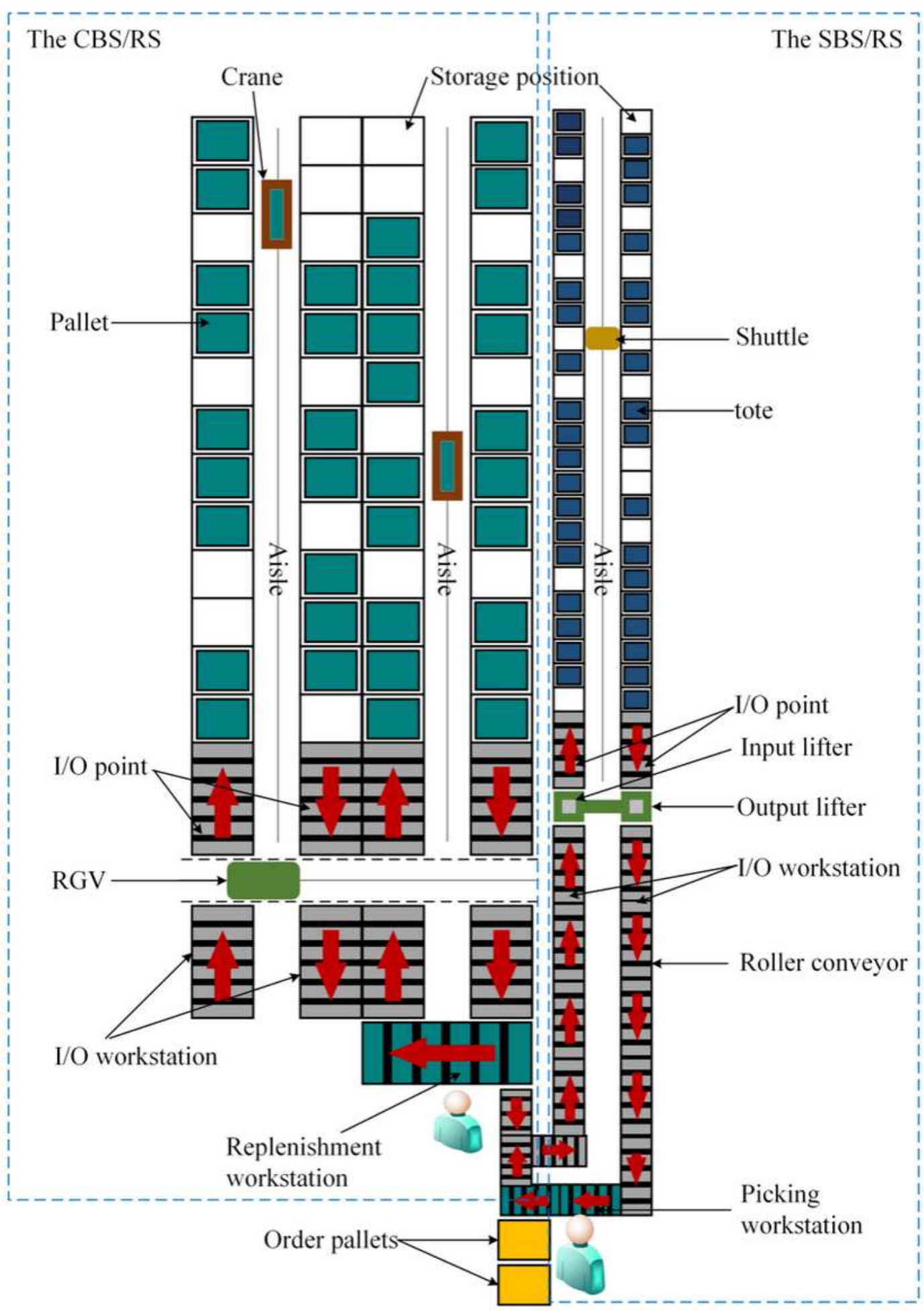

Figure 1

The top view description of the C\&SBS/RS 


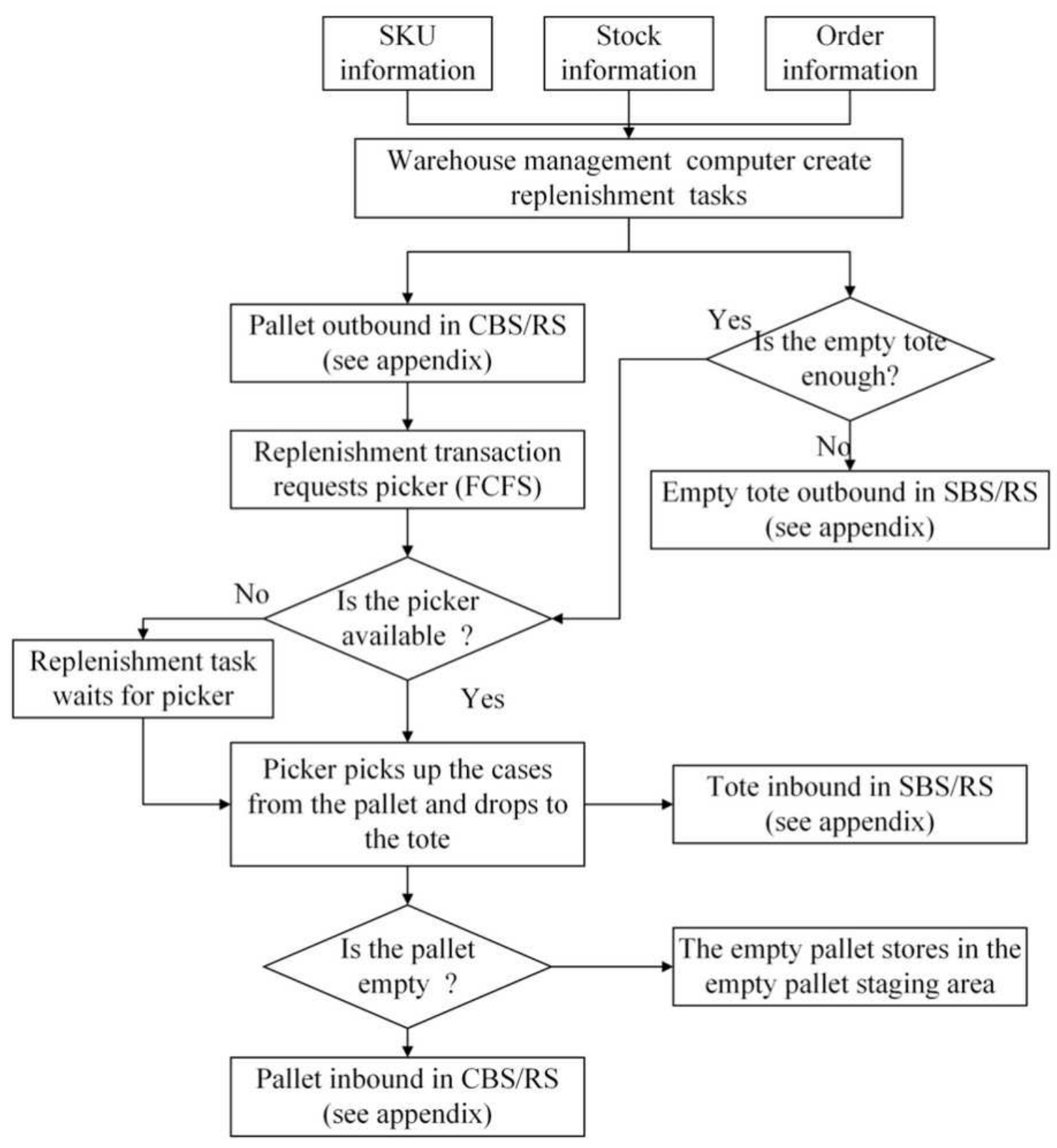

Figure 2

Flowchart of the replenishment transaction in C\&SBS/RS 


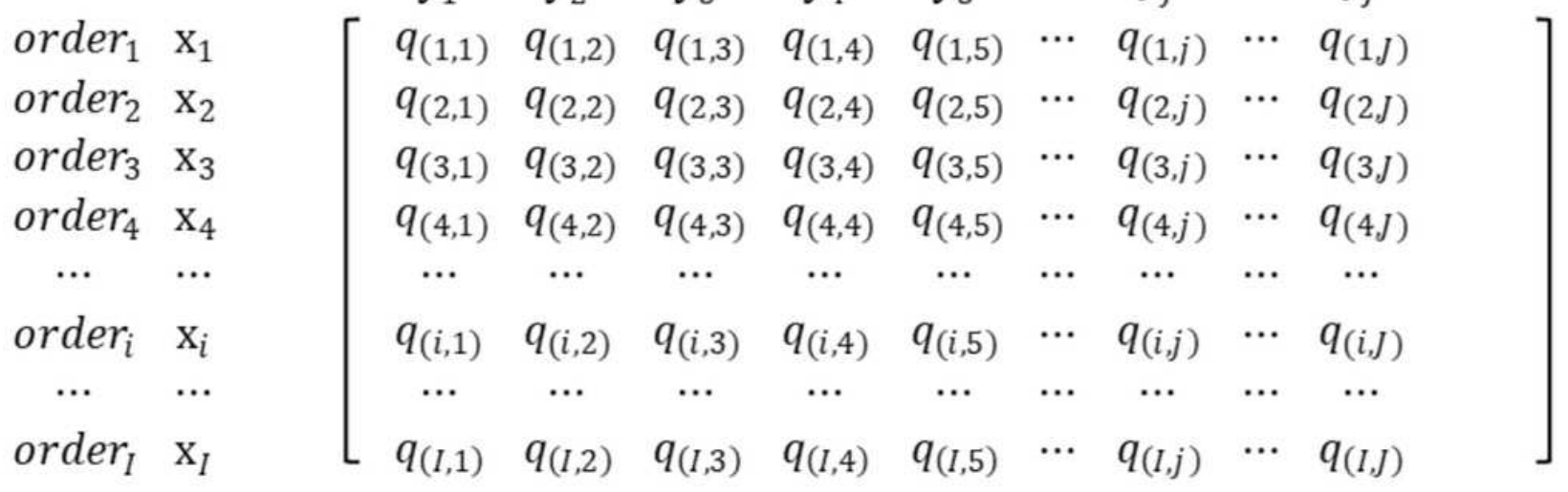

Figure 3

Definition of order matrix 


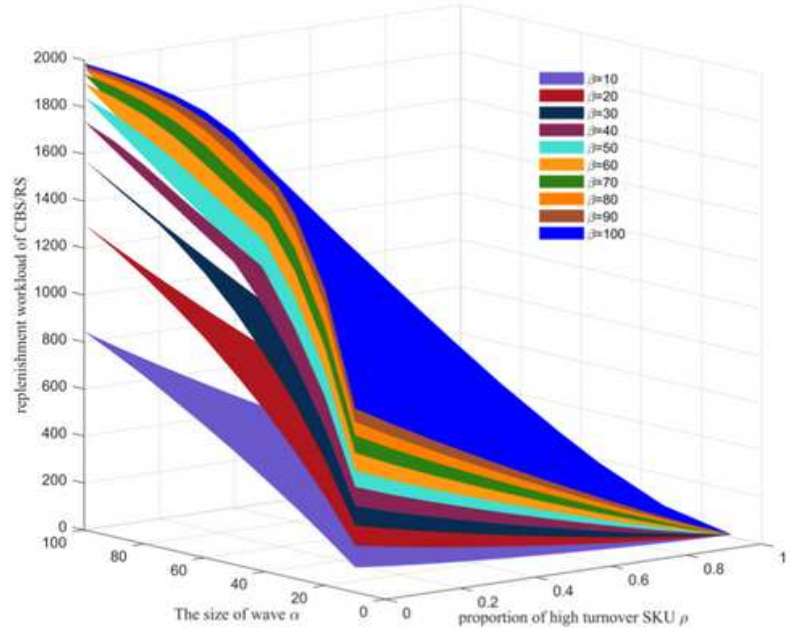

a.replenishiment workload of CBS/RS

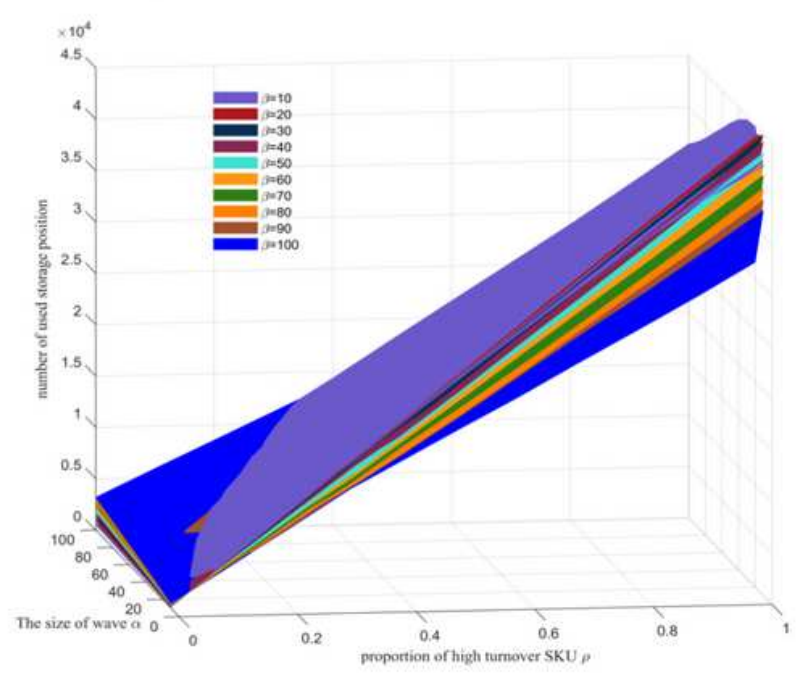

c.number of used storage position

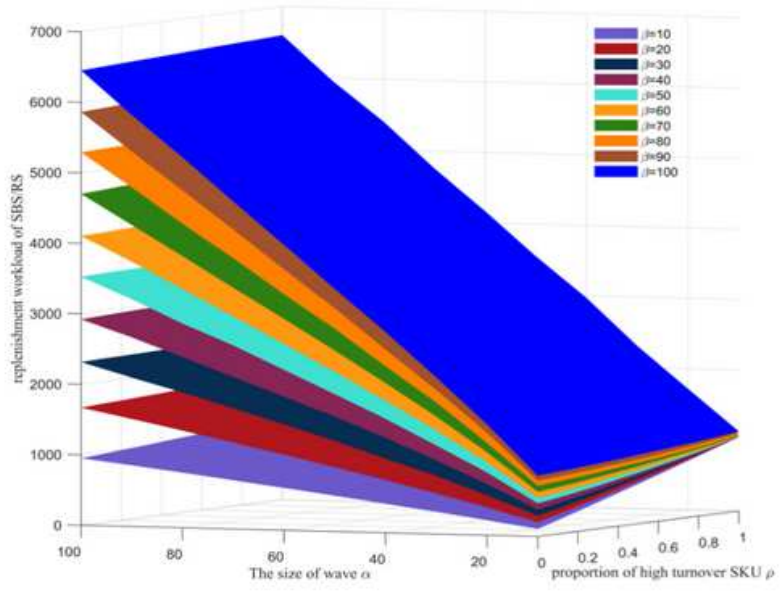

b.replenishiment workload of SBS/RS

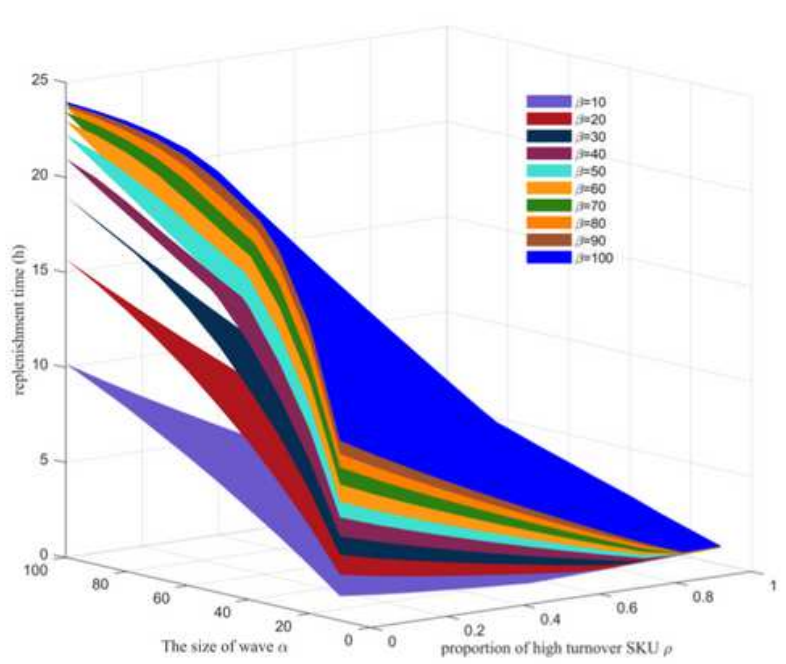

d.replenishment time(h)

Figure 4

effect of $y=1$ 


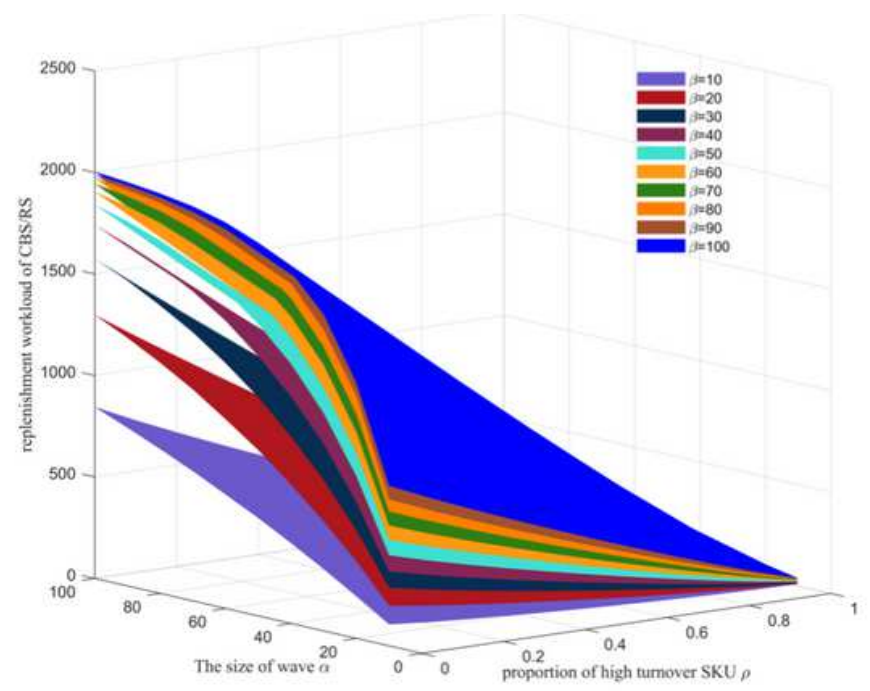

a.replenishiment workload of CBS/RS

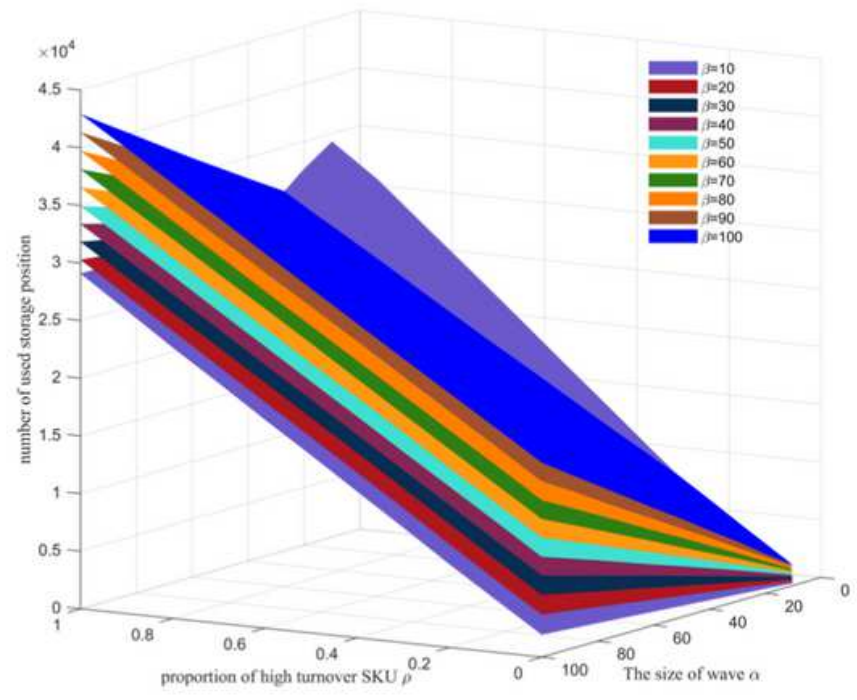

c.number of used storage position

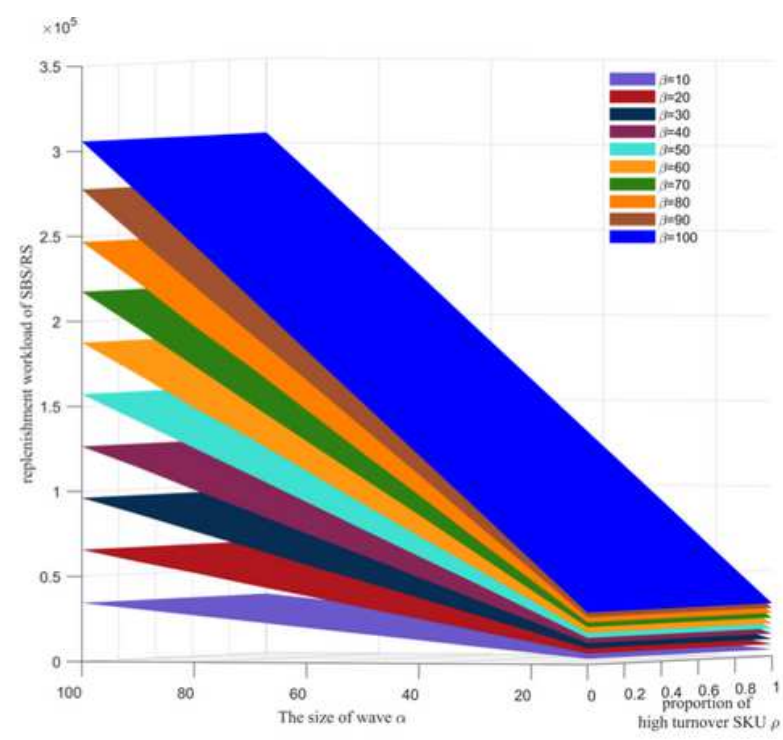

b.replenishiment workload of SBS/RS

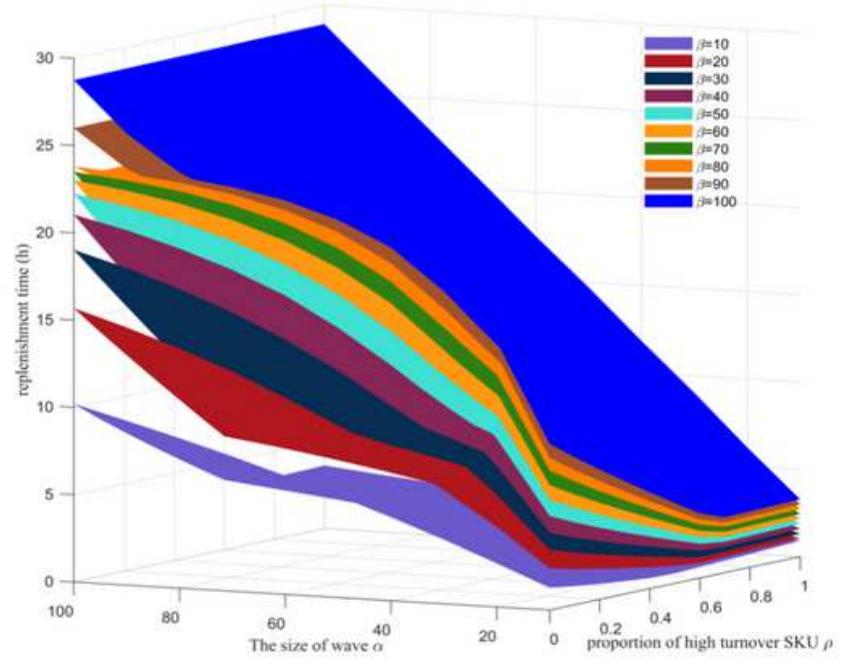

d.replenishment time(h)

Figure 5

effect of $\mathrm{Y}=\mathrm{U}[1,10]$ 


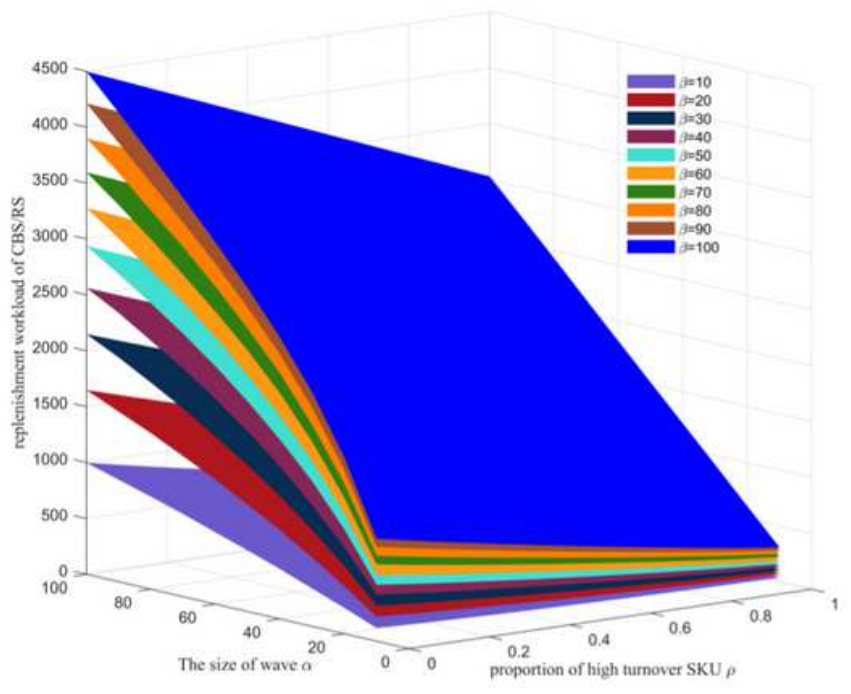

a.replenishiment workload of CBS/RS

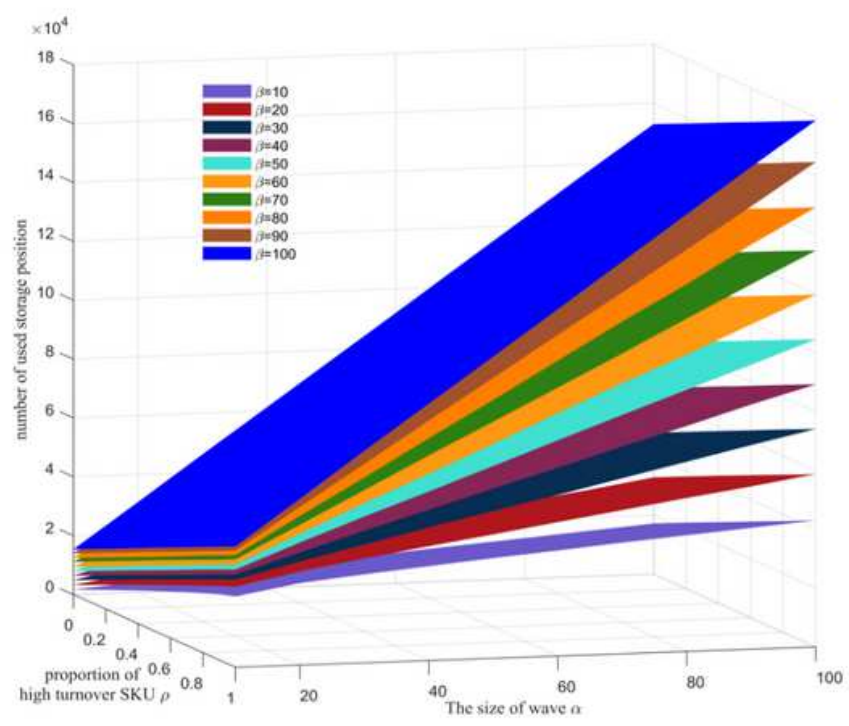

c.number of used storage position

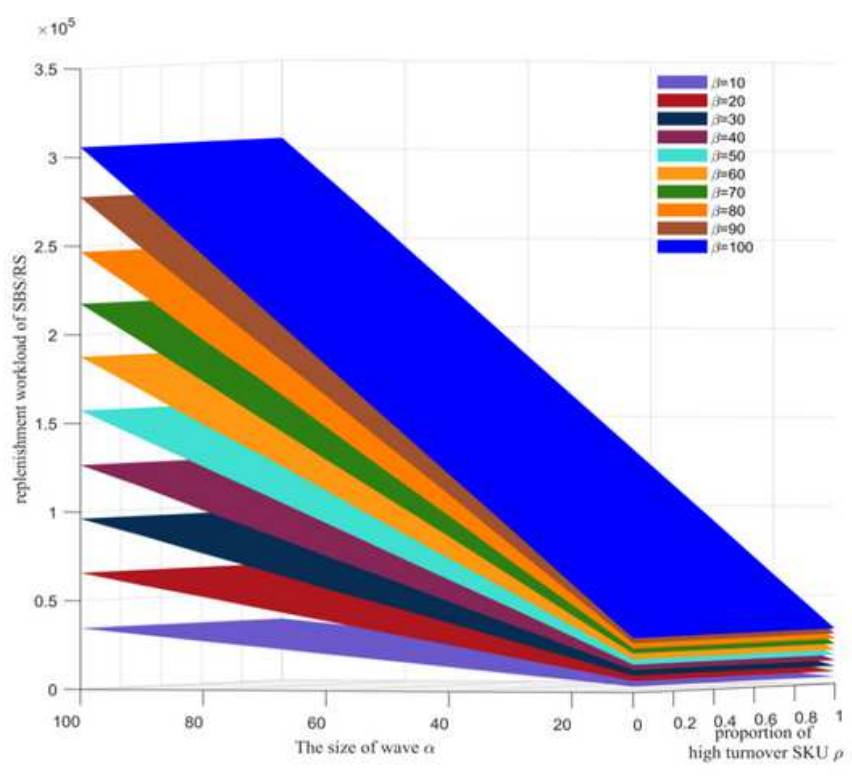

b.replenishiment workload of SBS/RS

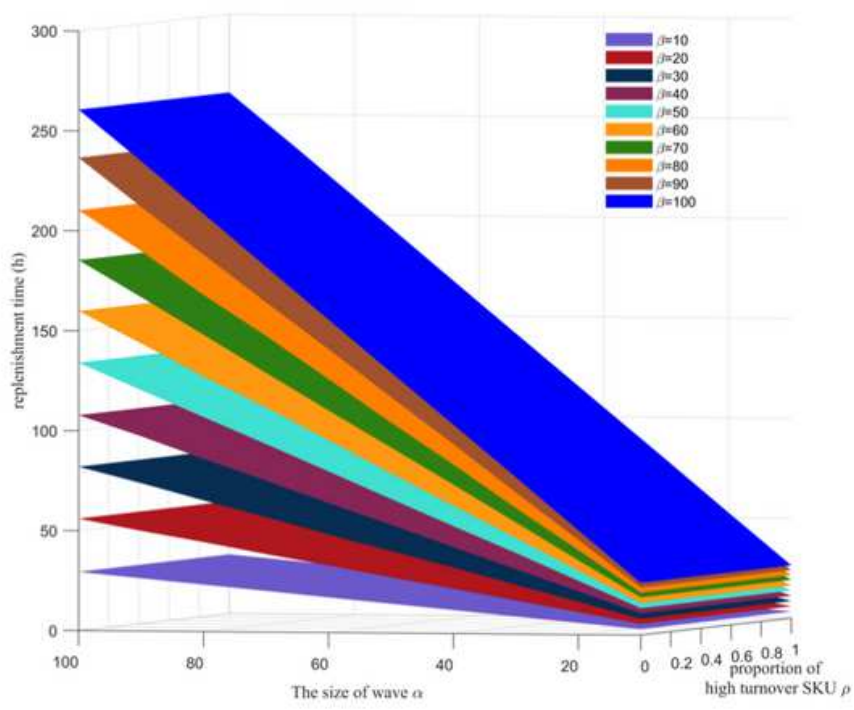

d.replenishment time(h)

Figure 6

effect of $\mathrm{Y}=U[1,50]$ 